\title{
The perception of healthcare providers on the quality of locally made drugs and imported drugs
}

\author{
Modupe I. Builders ${ }^{1 *}$, Philip F. Builders ${ }^{2}$ and Linda lliya ${ }^{2}$ \\ 1Department of Pharmacology, Faculty of Pharmacy, Bingham University, Karu, Nasarawa State, Nigeria. \\ ${ }^{2}$ Department of Pharmaceutics and Pharmaceutical Microbiology, Faculty of Pharmaceutical Sciences, Kaduna State \\ University, Kaduna, Kaduna State, Nigeria. \\ ${ }^{*}$ Corresponding author. Email: modupebuilders@yahoo.com
}

Copyright (C) 2019 Builders et al. This article remains permanently open access under the terms of the Creative Commons Attribution License 4.0, which permits unrestricted use, distribution, and reproduction in any medium, provided the original work is properly cited.

Received 18th March, 2019; Accepted 29th April, 2019

\begin{abstract}
Locally made drugs are an important policy way of reducing out-of-pocket expenditure on medicines. Therefore, negative perceptions of their quality affect utilization and raise issues of confidence and trust in medicines and health services. This study examines the perception of healthcare professionals to locally made drugs in relation to their understanding and opinions of generic and brand name drugs with the use of administering questionnaires to pharmacists, doctors, and nurses in tertiary hospitals in Kaduna State, Nigeria. Majority of the respondents were nurses (58.1\%), 50.1\% of the participant were females, they were in the age range of 20 to 30 years (37.8\%). $46.4 \%$ of the nurses strongly agreed that locally manufactured medicines are more affordable than the foreign made, $15.9 \%$ of the nurses strongly agreed that locally manufactured medicines produce more side effects/adverse events than the foreign made while $19.6 \%$ of the pharmacists strongly agreed that prescribing decision is influenced by medical representatives of foreign made medicines. The lack of consensus in the perceptions of locally made drugs and foreign drugs may result in friction among health professionals as well as discrimination in patronage of foreign and locally made drugs.
\end{abstract}

Keywords: Healthcare providers, imported drugs, locally made drugs, perception, quality.

\section{INTRODUCTION}

Drug use is a complex subject involving the prescriber, the patient (client) and pharmaceutical institutions. It is influenced by factors such as drug availability, prescribers' experience, and health budget, promotional activities of the pharmaceutical industry, cultural factors, communication system and the complex interaction between these factors. Hence, its study is more sociological than biomedical (WHO, 1985).

In most developing countries such as Nigeria, drugs remain the fulcrum of healthcare in order to meet the high demand in drugs due to the ever increasing population. The importation of drug products is the main stay due to the availability of only few indigenous pharmaceutical companies and also their relatively low throughput of indigenous manufacturers, hence the large imports of foreign manufactured drugs (Frost and Reich, 2009).

Time and again the importance of generic prescribing has been emphasized, primarily to reduce the cost of drugs (Mukherjee, 2013). A "generic" medicine is a multisource pharmaceutical product which is meant to be interchangeable with the comparator product (also known as proprietary, brand or innovator product) (WHO, 2005).

In Nigeria as well as many developing countries of the world, there is a strong apathy by the general populace for locally manufactured goods in relation to the similarly strong attraction to the foreign ones (Ogunnaike, 2010). Apart from the over the counter drugs (OTC), a large variety of the prescription drugs are used only after recommendation and prescription by a qualified health practitioner. For many patients especially the inpatients, drugs are used under supervision by appropriate healthcare professionals. The primary healthcare providers in Nigeria's healthcare system are essentially the medical doctors, pharmacists and nurses. The doctors, pharmacists and nurses are involved in the day to day coordination and management of the patients and their 
drugs need. Hence these professionals are overtly influential with respect to the type of the drugs the patients use (Khan et al., 2014).

The perception of these healthcare professional becomes very important especially during prescription writing, procurement and administration of drugs. Certain factors have been identified to influence the attraction of customers to foreign or locally manufactured products (Kotler and Armstrong, 2013). Some factors that strongly influence the attraction of customers to foreign made goods includes economic factors, historical and psychological forces, poor marketing strategies by local distributors and poor governmental control.

The perception of health care professionals, including doctors, nurses and pharmacists, regarding generic medicine substitution has not been investigated in Nigeria. Given the role of pharmacists in the management of medicines, including the selection and dispensing of medicines, they could be an important point of intervention for promoting generic medicine utilization in the health care system (Aivalli et al., 2018; Benton, 2014; Bruhn, 2013; Hoen and Pascual, 2015; Liberman, 2012; Travasso, 2014; Tadeg and Berhane 2012 ). This research was therefore carried out to investigate the views of healthcare professionals in Northern part of Nigeria on locally made drugs and imported drugs.

\section{MATERIALS AND METHODS}

\section{Materials}

200 copies of customized questionnaire, consisting of two sections; A and B. Section A comprised the demographic data of the respondents depicting the gender, age, profession, rank, department, place of practice, and years of working experience and Sections $B$ respectively contains likert-like questions that assesses the respondents' knowledge of generic drugs and the perception of healthcare professionals (doctors, pharmacists, and nurses) towards made in Nigerian drugs.

\section{Study design}

The survey research design was used. This approach was used because it was considered appropriate for collecting data from the public hospitals in Kaduna State with an intention to determine the perception of locally made drugs by healthcare professionals in Nigeria considering the variables under study.

\section{Sampling population}

The populations for this study were the selected healthcare professionals: pharmacists, doctors and nurses practicing at the selected hospitals in Kaduna State.

\section{Inclusion criteria}

The inclusion criteria comprise of the registered doctors, nurses and pharmacists.

\section{Exclusion criteria}

The exclusion criteria comprise of certain groups of the selected professionals: Intern pharmacists, corps members, and house officers. These were excluded as they possess minimal working experience and knowledge about medicines, hence their response will not accurately describe the perception of healthcare professionals on locally made drugs in Nigeria, as compared to the responses from the inclusion group.

\section{Sampling size and techniques}

A total of 200 questionnaires were issued to the nurses, pharmacists and doctors from each selected hospital to fill in for the study. The sample size is in line with the qualitative research which emphasizes depth of focus instead of quantity of information (Henning et al., 2004). This study used the probability sampling technique.

\section{Study site}

The study was carried out in five healthcare facilities located in Kaduna metropolis: Barau-Dikko Teaching Hospital (BDTH), Kaduna; Dr. Gwamna Awan General Hospital, Kakuri, Kaduna; National Ear Care Centre, Kaduna; General Hospital, Sabon Tasha, Kaduna; and Air Force Hospital, NAF Base Hospital, Kaduna.

\section{Ethical issues}

Ethical approval was sought from Health Research Ethics Committee (HREC), Kaduna State Ministry of Health and Human Services.

\section{Data analysis}

The research questions were analyzed with frequency distribution tables and bar charts. For the multiple responses, tally was used to count and the percentage was determined. The data were analyzed with the use of the Statistical Package for the Social Sciences (SPSS) Version 20.

\section{RESULTS}

\section{Gender distribution of the participants}

The results of the demographic evaluation on the gender 


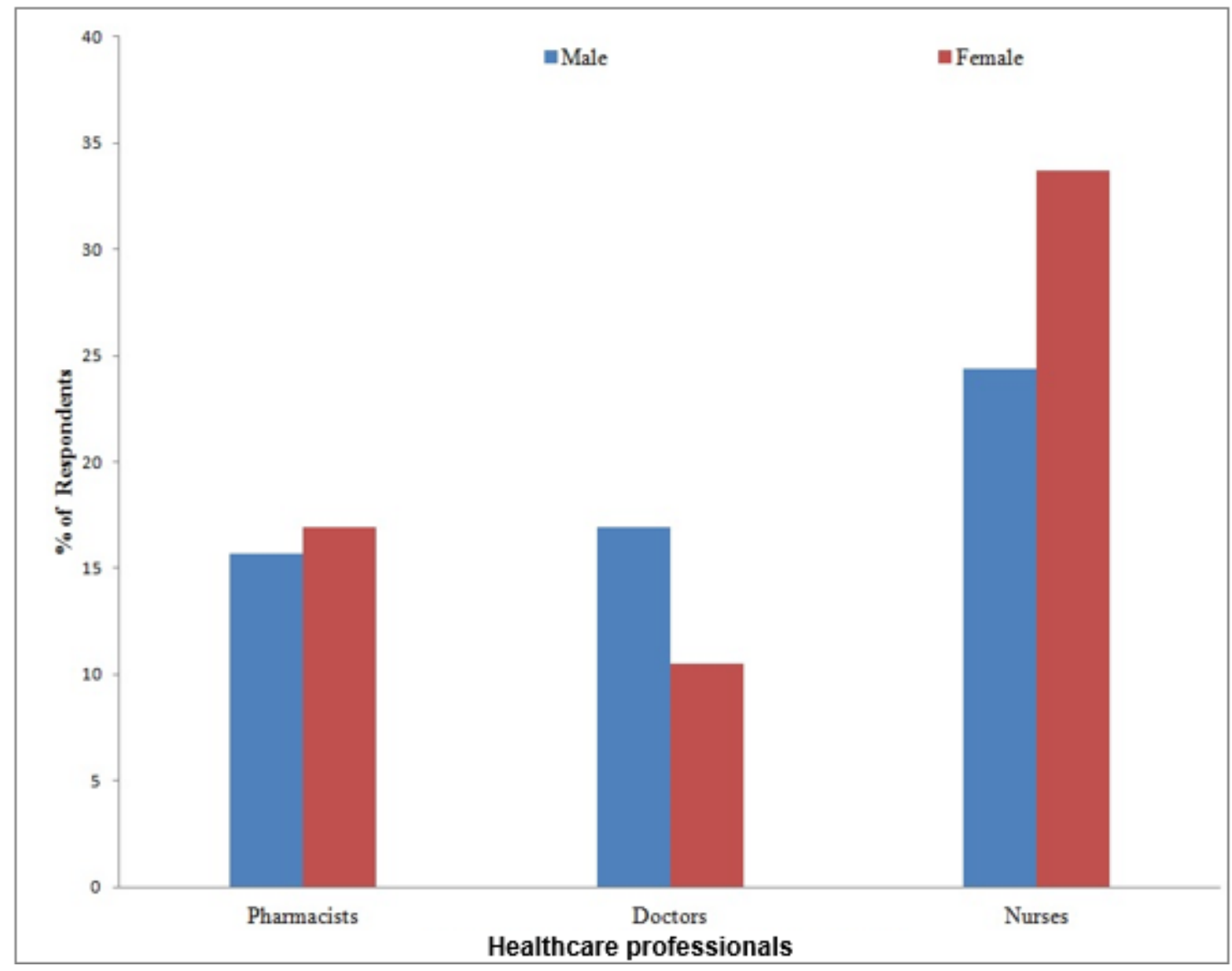

Figure 1. Gender distribution of participants.

of the respondents are presented in Figure 1. A total of 172 respondents participated in the study, 69 were nurses, and 56 were pharmacists while 47 were doctors. $15.7 \%$ of the pharmacists are male, while $16.9 \%$ are female. $16.9 \%$ of the doctors are male and $10.5 \%$ were female. Also, $24.4 \%$ and $33.7 \%$ of the nurses are male and female respectively.

\section{Age distribution of the participants}

Figure 2 indicates the demographic age representation of the respondents. The majority of the participants fall within the age group of 20 to 30 years, $42.9 \%$ of the pharmacists fall within the age group of 20 to 30 years, $40.4 \%$ of the doctors fall within the age group of 20 to 30 years, 31.9\% of the nurses fall within the age group of 20 to 30 years.

\section{Responses to perception P1-P4 (affordability, effectiveness and quality)}

Figure 3 illustrates that $46.4 \%$ of the nurses strongly agreed that locally manufactured medicines are more affordable than the foreign made, $23.2 \%$ of the pharmacists strongly agreed that that locally manufactured medicines are of the same effectiveness as the foreign made, $11.6 \%$ of the three health care professionals strongly agreed that locally manufactured generic medicines are of higher quality than the foreign made, while $26.1 \%$ of the nurses strongly agreed that locally manufactured medicines are of lower quality than foreign made.

\section{Responses to perception P5-P8 (side effects and good manufacturing practice)}

About $15.9 \%$ of the nurses strongly agreed that locally manufactured medicines produce more side effects/adverse events than the foreign made, $17.4 \%$ of the nurses strongly agreed that products produced by foreign multinational pharmaceutical companies are of better quality than local company products, $19.2 \%$ of the three health care professionals strongly agreed that only few local companies produce quality generic medicines while $9.3 \%$ of the pharmacists, doctors and nurses strongly agreed that all the local companies in Nigeria do not follow the Good Manufacturing Practice (GMP) guidelines as the foreign manufacturers as presented in Figure 4. 


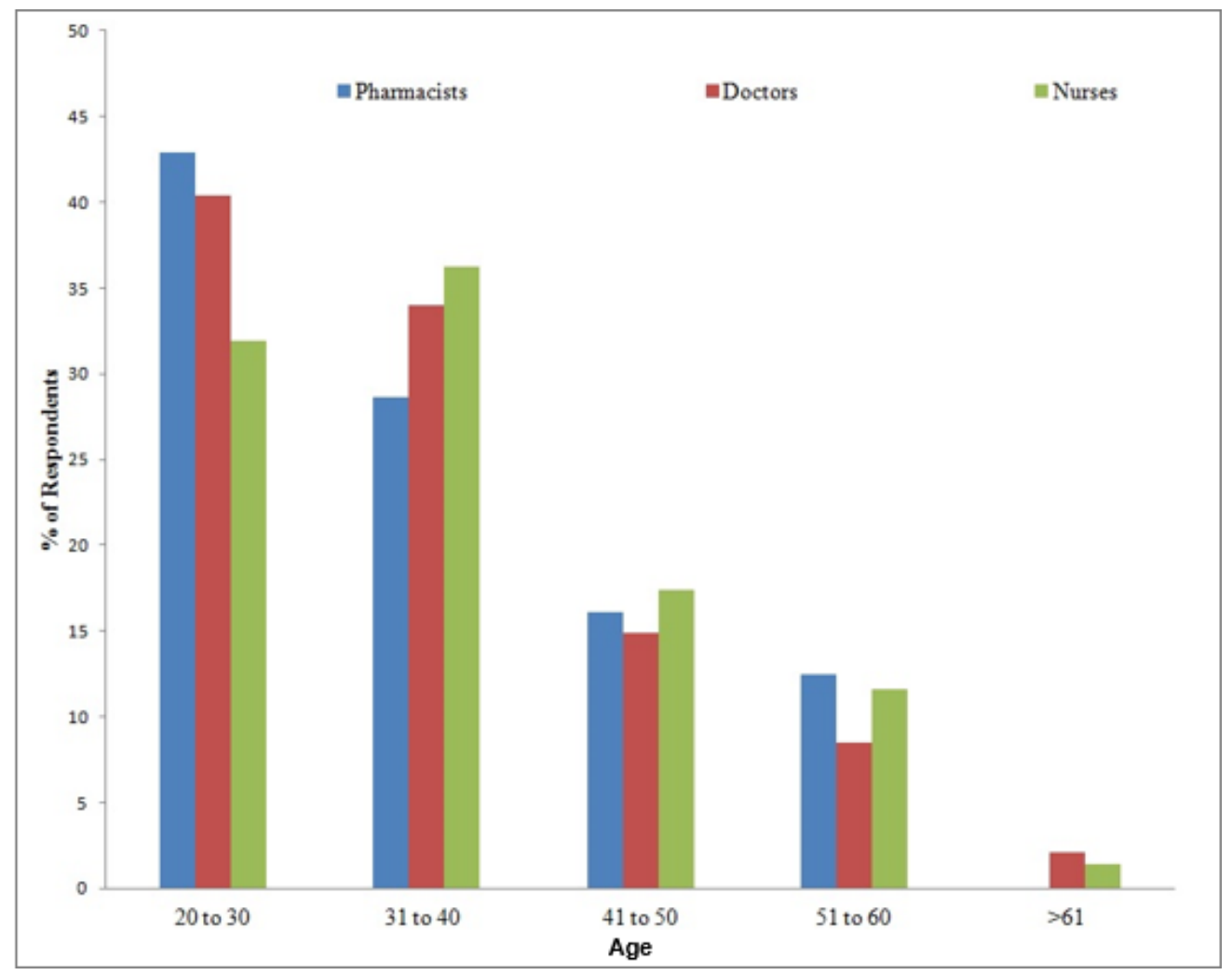

Figure 2. Age distribution of participants.

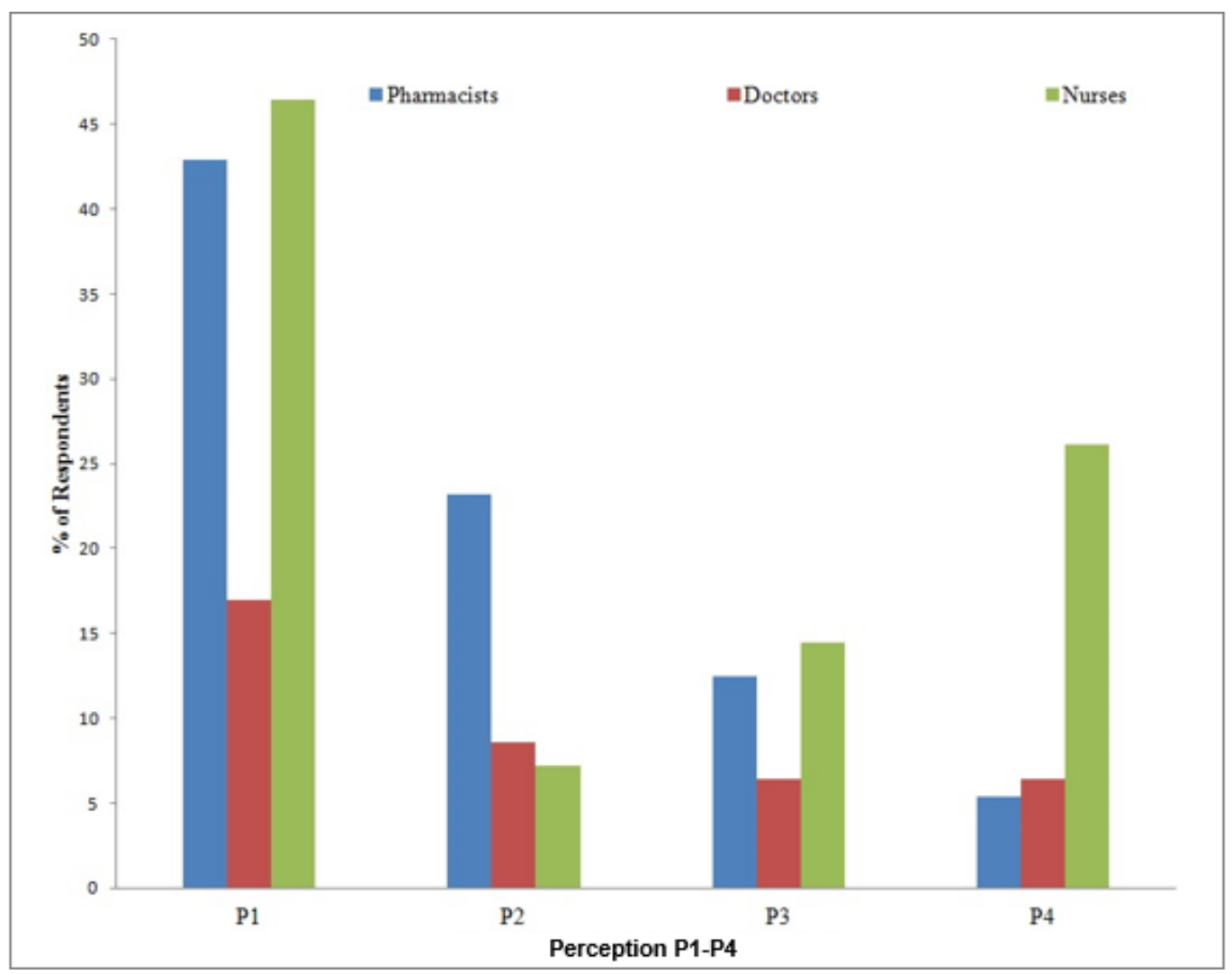

Figure 3. Response to perception P1-P4. 


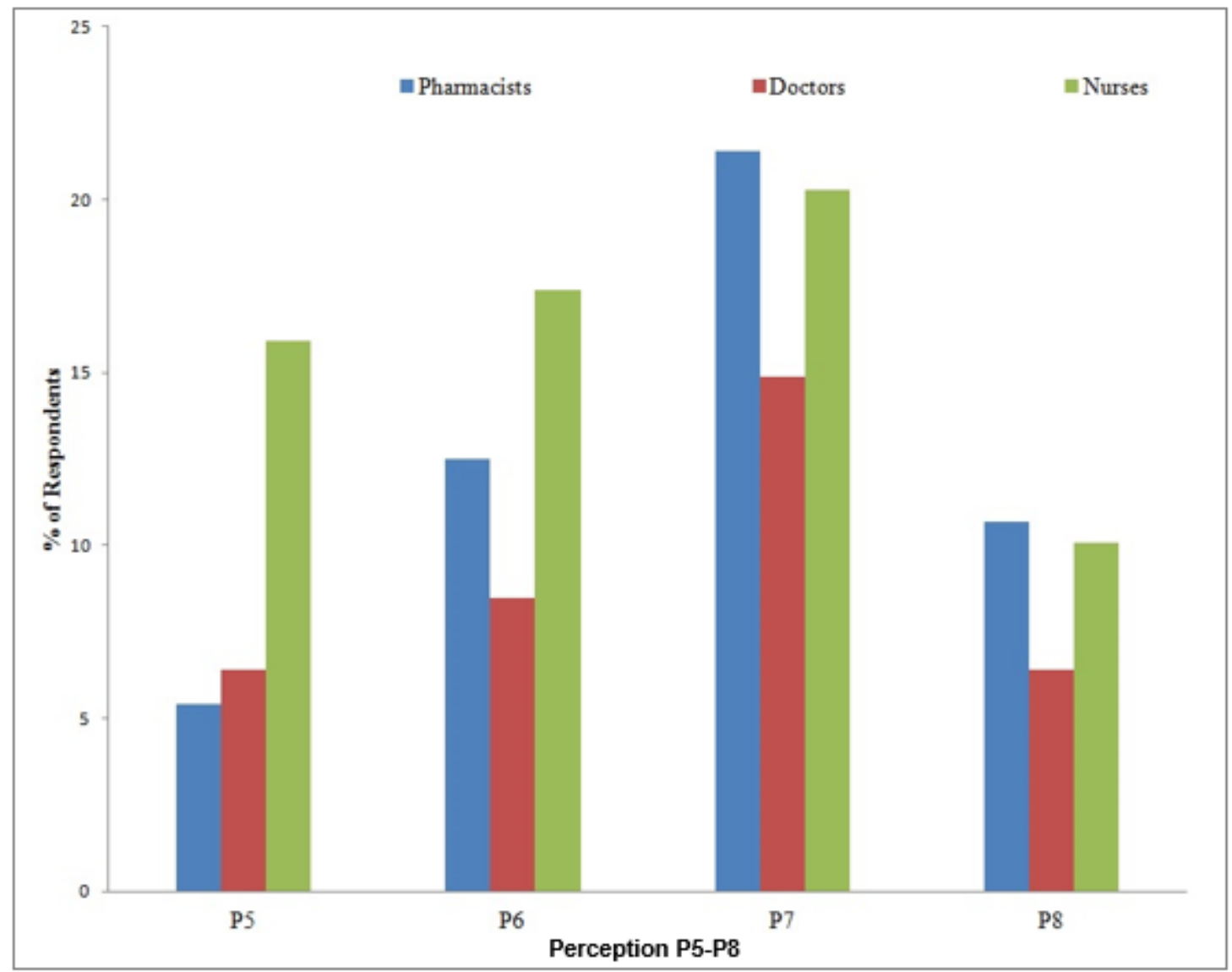

Figure 4. Response to perception P5-P8.

\section{Responses to perception P9-P12 (prescribing decision, confidence and procurement)}

Figure 5 indicates that $19.6 \%$ of the pharmacists strongly agreed that prescribing decision is influenced by medical representatives of foreign made medicines, $18.7 \%$ of the three health care professionals strongly agreed that locally manufactured medicines are meant for poor, $27.9 \%$ of the doctors, pharmacists and nurses strongly agreed that confidence should be built in the patients and health professionals on the use locally made medicines while $23.8 \%$ of the three health care professionals strongly agreed that it is easier to procure locally brand name medicine .

\section{DISCUSSION}

The study sought to investigate the perception of locally made drugs by health professionals in Nigeria: this was a prospective study in which pharmacists, doctors, and nurses were recruited in selected hospitals in Kaduna, Nigeria. Of the thirteen health professionals in Nigeria, pharmacists, doctors, and nurses were selected as the study population because they are the ones that have direct access to drugs while discharging their duties (While et al., 2005); doctors diagnose and prescribe medicines, pharmacists dispense the medicines (Kiel and Mccord, 2005) to be administered to the patient by the nurse (Armitage and Knapman, 2003). These three healthcare professionals are considered to be major contributors in improving public health by giving extensive advice on medicine use to ensure safe and responsible self-care, promote medication adherence as well as encourage healthy life-styles through appropriate health education strategies (Jones et al., 2004).

From the result of the demographic data, the number of nurses, pharmacists and doctors in the different selected hospitals varies, probably according to the facility and the size of patients visiting the hospital. Nurses were of greater number, followed by pharmacists, and then doctors. Also, greater percentage of the pharmacists $(51.8 \%)$ and nurses $(58.0 \%)$ were female. Majority of the doctors $(61.7 \%)$ were male. This was in line with WHO specification for the density of health professionals per 10,000 populations. The density of physicians (per 10,000 population) is 4.0, while that of nurses and midwives (per 10,000 population) is 16.1 (WHO, 2014). Most nurses are female partly 


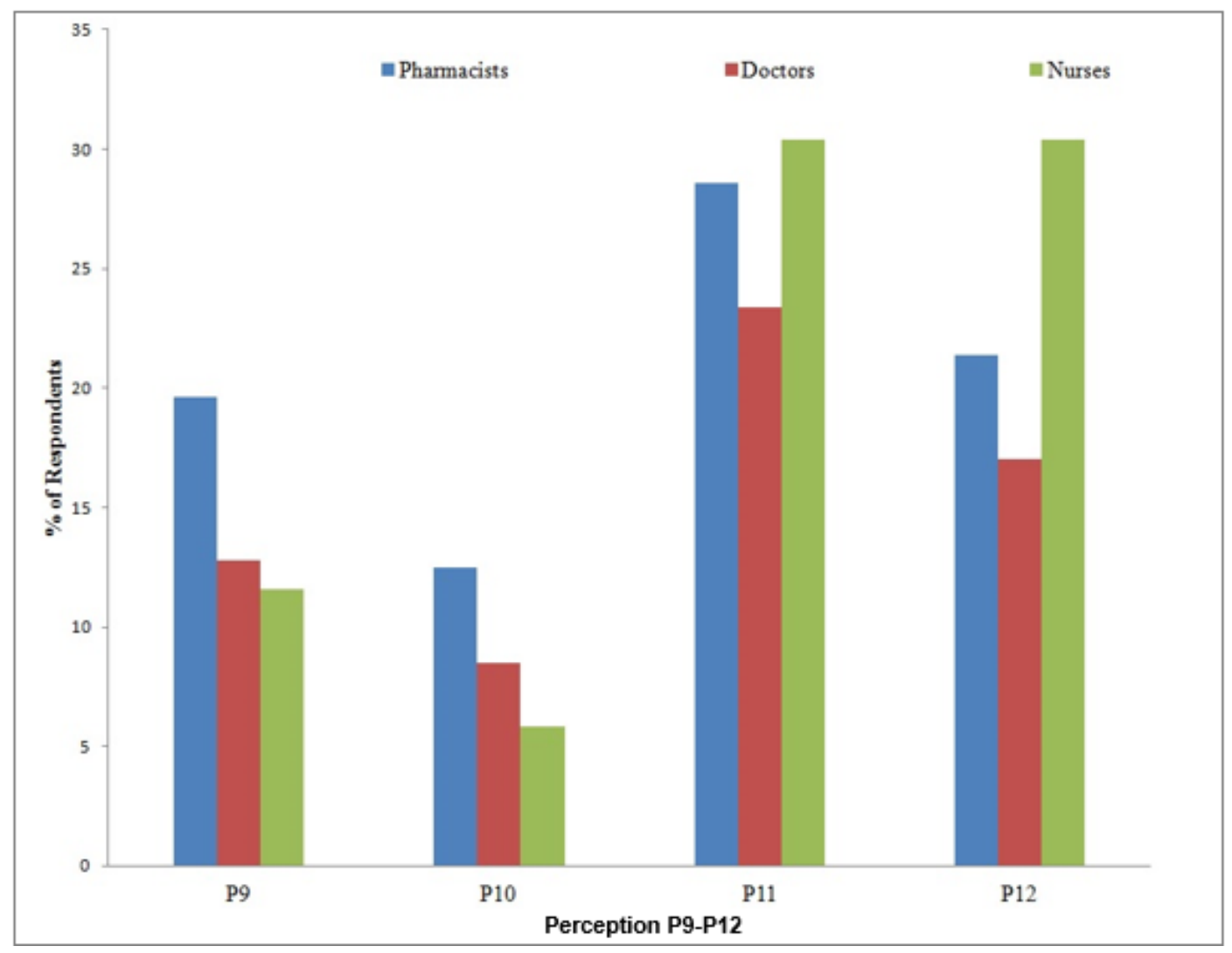

Figure 5. Response to perception P9-P12.

because of continued stereotyping about what a nurse looks like, when people think of a nurse perhaps, they do think of a woman. Some of the details do not help - the term matron is weird.

Majority of the respondents were within the age group of 20 to 30 years. This showed that most of the pharmacists, nurses and doctors who responded were young graduates and is expected to be more equipped with information about drugs; this could have been as a result of the early school leaving ages.

All respondents agreed that locally made drugs are more affordable than foreign drugs, because the raw materials used in the manufacture of such drugs are readily available and cheaper coupled with the fact that there is waiver on import duties for pharmaceutical raw materials used for local manufacture (Kaplain, and Laing 2005). In Nigeria, outlays on medication account for a huge percentage of expenditures on healthcare. As a result, the availability of medications in the Essential Medicine List at affordable prices must be included in the list of topics addressed by public health policies. The effectiveness of locally made medicines was said by the nurses and doctors to be inferior to those that are imported. The pharmacists, however, held a contrary opinion. However, the pharmacists and nurses believe that locally made medicines are of lower quality than foreign ones, the doctors do not believe in this assertion either. This implies that they (doctors) are of the opinion that locally made medicines may or may not be of lower quality than imported ones, depending on the outcome achieved by experience of the medical practitioner. Majority of the pharmacists believed that locally manufactured medicines are of the same effectiveness as the foreign made. The survey of physicians, pharmacists and patients on generic substitution indicated that pharmacists in general supported the use of locally made drugs. The most important factors that pharmacists cited for selecting a product were quality, price and supplier consistency (AlJazairi et al., 2008).

As regards the side effects of locally made drugs, pharmacists and doctors agreed that these medicines do not have severe side effects as compared to the foreign ones, although the nurses were of the opinion that locally made drugs possess severe side effects than foreign made medicines. The present study showed that products produced by foreign multinational pharmaceutical companies are of better quality than local company products, prescribing decision is influenced by medical representatives of foreign made medicines. Also, studies have shown that pressure from pharmaceutical companies may be one of the reasons for writing trade name, as many drugs are sold in the market in trade names, therefore prescribers do not have much option in this regard (Builders et al., 2011). It is easier to procure locally brand 
name medicine, and only few local companies produce quality generic medicines. The three professionals stand on the same perception. Strict adherence to Good Manufacturing Practice (GMP) guidelines by pharmaceutical industries ensures the manufacture of medicines of good quality (Brhlikova et al., 2017). It was shown by the doctors and pharmacists' response that the entire local companies in Nigeria does not follow the Good Manufacturing Practice (GMP) guidelines as the foreign manufacturers, whereas the nurses held a contrary opinion.

\section{Conclusion}

The current study showed good perception towards locally made medicines among healthcare professionals in Kaduna. It also highlighted that locally made medicines were widely accepted by the healthcare professionals and finally the perception of healthcare professionals on indigenous and imported drugs was determined successfully.

\section{Recommendations}

Since negative perceptions of locally produced drug can have major implications for healthcare utilization as well as for the continuity of care in public facilities, therefore, it is recommended that huge investments should be made on the promotion of locally made drugs by pharmaceutical companies instead of foreign products. Also, health care providers should be encouraged to prescribe locally produced drug through organization of workshops.

\section{CONFLICT OF INTEREST}

The authors declare that they have no conflict of interest.

\section{ACKNOWLEDGEMENT}

The authors sincerely thank all the staff of the five health care facilities located in Kaduna for their assistance in the collection of the data.

\section{REFERENCES}

Aivalli, P. K., Elias, M. A., Pati, M. K., Bhanuprakash, S., Munegowda, C., Shroff, Z. C., \& Srinivas, P. N. (2018). Perceptions of the quality of generic medicines: implications for trust in public services within the local health system in Tumkur, India. BMJ Global Health, 2(Suppl 3), e000644.

Al-Jazairi, A. S., Bhareth, S., Eqtefan, I. S., \& Al-Suwayeh, S. A. (2008). Brand and generic medications: are they interchangeable? Annals of Saudi Medicine, 28(1), 33-41.

Armitage, G., \& Knapman, H. (2003). Adverse events in drug administration: a literature review. Journal of Nursing
Management, 11(2), 130-140.

Benton, D., \& Williamson, L. (2014). Fake medicines are everybody's business. Australian Nursing and Midwifery Journal, 21(10), 26.

Brhlikova, P., Harper, I., \& Pollock, A. (2007). Good manufacturing practice in the pharmaceutical industry. Paper delivered in workshop on tracing pharmaceuticals in South Asia. Unpublished working Paper.

Bruhn, C. (2013). The fight against counterfeit drugs. Deutsche Medizinische Wochenschrift (1946), 138(47), 2396-2397.

Builders, M. I., Okonta, J. M., \& Aguwa, C. N. (2011). Prescription patterns of analgesics in a community hospital in Nsukka. Journal of Pharmaceutical Sciences and Research, 3(12), 1593-1598.

Frost, L. J., \& Reich, M. R. (2009). Creating access to health technologies in poor countries. Health Affairs, 28(4), 962-973.

Henning, E., Rensburg, W. V., \& Smit, B. (2004). Finding your way in qualitative research. Van Schaik Publisher. p.179.

Hoen, E. T., \& Pascual, F. (2015). Counterfeit medicines and substandard medicines: Different problems requiring different solutions. Journal of Public Health Policy, 36(4), 384-389.

Jones, T. (2016). Outcome measurement in nursing: Imperatives, ideals, history, and challenges. OJIN: The Online Journal of Issues in Nursing, 21(2), 1-11.

Kaplain, W., \& Laing, R. (2005). Local production of pharmaceuticals: industrial policy and access to medicines. The International Bank for Reconstruction and Development / The World Bank 1818 H Street, NW Washington, DC 20433.

Khan, A. N., Khan, M. U., Shoaib, M. H., Yousuf, R. I., \& Mir, S. A. (2014). Practice nurses and pharmacists: a perspective on the expectation and experience of nurses for future collaboration. Oman Medical Journal, 29(4), 271.

Kiel, P. J., \& McCord, A. D. (2005). Pharmacist impact on clinical outcomes in a diabetes disease management program via collaborative practice. Annals of Pharmacotherapy, 39(11), 1828-1832.

Kotler, P., \& Armstrong, G. (2013). Principles of Marketing. 14th Edition, Boston: Pearson. p. 174.

Liberman, J. (2012). Combating counterfeit medicines and illicit trade in tobacco products: minefields in global health governance. The Journal of Law, Medicine \& Ethics, 40(2), 326-347.

Mukherjee, R. (2013). Prescribe generic drugs: $\mathrm{MCl}$ to doctors. The Times of India. Available at articles.timesofindia.indiatimes.com/2018-01-

02/india/36576717_1_generic-drugs-generic-medicinesgeneric-versions.

Ogunnaike, O. (2010). Nigerians' perception of locally made products: A study on textile fabrics Consumers in Kaduna State. Petroleum-Gas University of Ploiesti Bulletin, LXII, 3036.

Tadeg, H., \& Berhane, Y. (2012). Substandard and counterfeit antimicrobials: recent trends and implications to key public health interventions in developing countries. East African journal of public health, 9(2), 85-89.

Travasso, C. (2014). Counterfeit and substandard drugs in India may be smaller problem than claimed, say government findings, The BMJ, 348-360.

While, A., Shah, R., \& Nathan, A. (2005). Interdisciplinary working between community pharmacists and community nurses: the views of community pharmacists. Journal of Interprofessional Care, 19(2), 164-170.

World Health Organization (WHO) (1987). Report of the conference of experts on the rational use of drugs. 25-29th 
November 1985, World Health Organization, Geneva.

World Health Organization (WHO) (2005). Counterfeit and substandard drugs. Frequently asked questions. (http://www.who.int/medicines/services/counterfeit/faqs/en/).

Accessed 3 October 2017.
World Health Organization (WHO) (2014). Global health observatory, health workforce statistics. Geneva: World Health Organization. Retrieved on 10 December 2014 from http://www.who.int/hrh/statistics/hwfstats. 